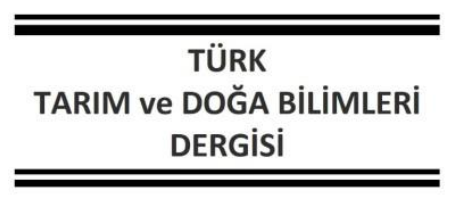

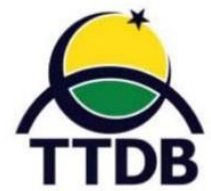

www.dergipark.gov.tr/turkjans

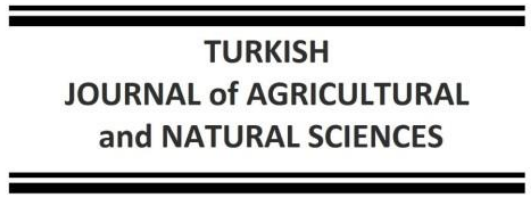
(1) \title{
Araştırma Makalesi \\ - \\ Nagami Çeşidi Kamkat Meyvelerinin Fiziko-Mekanik Karakteristikleri ile Biyoaktif Özelliklerinin Belirlenmesi
}

\author{
Esra Nur GÜL ${ }^{1 *}$, Ebubekir ALTUNTAŞ ${ }^{1}$, Osman Nuri ÖCALAN² \\ ${ }^{1}$ Tokat Gaziosmanpaşa Üniversitesi, Ziraat Fakültesi, Biyosistem Mühendisliği Bölümü,Tokat \\ ${ }^{2}$ Tokat Gaziosmanpaşa Üniversitesi, Ziraat Fakültesi, Bahçe Bitkileri Bölümü,Tokat \\ *Sorumlu Yazar: esranur.gul4219@gop.edu.tr
}

Geliş Tarihi: 17.06.2021 Düzeltme Geliş Tarihi: 22.08.2021 Kabul Tarihi: 14.10.2021

Öz

Bu çalışmada, besin değeri yüksek ve kolay erişilebilir biyoaktif madde potansiyeli olan kamkat meyvelerinin bazı biyoteknolojik karakteristikleri (fiziksel, mekanik, renk ve biyoaktif özellikler) incelenmiştir. Meyvelerin biyoteknolojik karakteristiklerinden fiziksel ve mekanik özellikleri içerisinde boyut özellikleri, geometrik ortalama çap, küresellik, yüzey alanı, sürtünme özellikleri, mekanik davranışları ile renk özellikleri belirlenmiştir. Bazı kimyasal özellikleri ise toplam fenolik, antioksidan kapasitesi, toplam flavonoid, C vitamini, $\mathrm{pH}$, titre edilebilir asitlik ve suda çözünür kuru maddedir. Çalışmada kullanılan meyvelerin nem içeriği yaş baza göre 81.01 (\% y.b.) olarak belirlenmiştir. Kamkat meyvesinin uzunluk, genişlik, kalınlık değerleri sırasıyla 33.76 $\mathrm{mm}, 23.24 \mathrm{~mm}, 22.77 \mathrm{~mm}$ olarak belirlenmiştir. Meyvelerin geometrik ortalama çap, küresellik ve yüzey alanı değerleri sırasıyla $26.04 \mathrm{~mm}, \% 77.32$ ve $2141.94 \mathrm{~mm}^{2}$ olarak belirlenmiştir. $L^{*}, a^{*}, b^{*}$ renk değerleri hasat sonrasındaki taze meyvelerin kabuk yüzeyi için sırası ile 59.89, 23.38 ve 54.86 olarak belirlenirken, meyve eti için bu değerler sırasıyla 60.01, 5.43 ve 34.00 olarak belirlenmiştir. Toplam fenolik, antioksidan kapasitesi, toplam flavonoid, C vitamini değerleri sırasıyla $116.19 \mu \mathrm{g} \mathrm{GAE} \mathrm{g}^{-1}, 2.98 \mu \mathrm{mol} \mathrm{TE} \mathrm{g}^{-1}, 34.04 \mathrm{mg} \mathrm{KE} \mathrm{L}^{-1}, 308.67 \mathrm{mg}$ $\mathrm{L}^{-1}$ olarak belirlenmiştir. Biyo-teknolojik karakteristikler, kamkat meyvelerinin temizleme, ayırma, paketleme, depolama ve işleme esnasında ve hasat sonrası tüketiciye sunulmasında kalitesinin korunması açısından dikkate alınması gereklidir.

Anahtar kelimeler: Nagami, kamkat, küresellik, kroma, sertlik, antioksidan, flavonid

\section{Determination of Physico-Mechanical Characteristics and Bioactive Properties of Nagami Kumquat Fruits}

\begin{abstract}
In this study, some biotechnical characteristics (physical, mechanical, color and bioactive properties) of kumquat fruits, which are high nutritional value and easily accessible bioactive substance potential, were investigated. Among the physical and mechanical properties from biotechnical properties the fruits; size dimensions, geometric mean diameter, sphericity, surface area, friction properties, mechanical behaviour and color properties were determined. Some chemical properties are total phenolic, antioxidant capacity, total flavonoid, vitamin $\mathrm{C}, \mathrm{pH}$, titratable acidity and solid soluble content. The moisture content of the fruits used in the study was determined as 81.01 (\% y.b.) according to the wet base. The length, width and thickness values of the kumquat fruit were determined as $33.76 \mathrm{~mm}, 23.24 \mathrm{~mm}, 22.77 \mathrm{~mm}$, respectively. The geometric mean diameter, sphericity and surface area values of the fruits were determined as $26.04 \mathrm{~mm}, 77.32 \%$ and 2141.94 $\mathrm{mm}^{2}$, respectively. $L^{*}, a^{*}, b^{*}$ color values were determined as 59.89, 23.38 and 54.86 for the skin of fresh fruits after harvest, respectively, while these values for fruit pulp were determined as 60.01, 5.43 and 34.00, respectively. Total phenolic, antioxidant capacity, total flavonoid, vitamin $C$ values were determined as 116.19 $\mu \mathrm{g} \mathrm{GAE} \mathrm{g}{ }^{-1}, 2.98 \mu \mathrm{mol} \mathrm{TE} \mathrm{g}{ }^{-1}, 34.04 \mathrm{mg} \mathrm{KE} \mathrm{L}^{-1}, 308.67 \mathrm{mg} \mathrm{L}^{-1}$, respectively. Bio-technological characteristics should be taken into account in order to preserve the quality of kumquat fruits during cleaning, sorting, packaging, storage, processing and post-harvest presentation to the consumer.
\end{abstract}

Key words: Nagami, kumquat, sphericity, croma, hardness, antioxidant, flavonid 


\section{Giriş}

Kamkat, Rutaceae familyasından Fortunella cinsindeki turunçgil türlerinden biridir. Fortunella margarita [Lour.] Swingle; Nagami kamkat veya oval kamkat olarak da bilinmektedir; 2-5 çekirdekli, hoş aromalı ve koyu turuncu renkli bir kamkat türüdür (Jarvis, 2017). Kabuğuyla birlikte bütün olarak tüketilebilmesi, diğer narenciyelere nazaran fenolik bileşikler gibi biyoaktif maddelerin alımında kamkat meyvesine üstünlük sağlamaktadır (Olcay ve Demir, 2019). Kamkat meyvesinin Antalya bölgesinde üretimi giderek yaygınlaşmaktadır. Batı Akdeniz Tarımsal Araştırmalar Enstitüsü Müdürlüğü (BATEM)'e ait narenciye bahçelerinde yıllık 10 tona yakın meyve toplanırken, il genelindeki kamkat üretim rekoltesi 3 bin tona ulaştığı söylenmektedir (Anonim, 2021).

Kamkat, özellikle ilaç endüstrisinde, farmasötik alanda ya da gıda endüstrisinde, fonksiyonel gıda üretimine elverişli olan bir öneme sahiptir. Çiğ olarak tüketildiği gibi reçel, marmelat, meyve suyu, şekerleme, kek ve pasta yapımında kullanılabilmekte, özellikle Çin lokantalarında yemeklerin sonunda yenilen önemli bir tatlı çeşididir. Kamkat, C vitamini yönünden zengin bir meyvedir. 100 gramında 43.9 miligram C vitamini içermektedir. Tıbbi açıdan kas ve doku oluşumu için gerekli bu vitamin, diğer mineral ve vitaminlerin daha iyi kullanılmasına da yardım etmektedir (Anonim, 2016).

Ürün kalitesi bakımından hasatta ve hasat sonrasında, tarımsal materyallerin biyoteknolojik özellikleri kapsamında geometrik, gravimetrik, renk özellikleri sürtünme, kuvvet karşısında gösterdiği mekanik direnç ve kimyasal özellikleri belirlenebilmektedir. Hasat sonrası uygulanacak teknolojik işlemlerde kullanılacak makine ve sistemlerin iş veriminin artırılmasında tarımsal ürünlerin biyoteknolojik özelliklerinin bilinmesi oldukça önemlidir (Saracoglu ve Altuntaş, 2021).

Turunçgiller ailesinin bir bireyi olan kamkat özellikle son yıllarda daha çok ilgi görmeye başlamıştır. Bu meyvede biyoteknik özellikler üzerine çok az sayıda çalışmanın bulunduğu yapılan literatür taramasında ortaya çıkmaktadır. Jaliliantabar ve ark. (2013), kamkat meyvelerinin fiziksel ve mekanik özelliklerini belirlemişler ancak; Nagami çeşidinde meyvelerinin fiziksel, renk, mekanik ve kimyasal gibi biyoteknolojik özellikleri ile birlikte incelenen bir çalışmaya ulaşılamamıştır. $\mathrm{Bu}$ çalışmada ise, Nagami çeşidi kamkat meyvelerinin fiziksel, renk, farklı hız ve eksenlerdeki mekanik davranışı ile biyoaktif gibi biyoteknolojik özellikleri birlikte incelenmiştir. Böylece, Nagami çeşidi kamkat meyvelerinin biyoteknolojik karakteristiklerinin belirlenmesi, temizleme, ayırma, paketleme, depolama ve işleme esnasında ve hasat sonrası tüketiciye sunulmasında kalitesinin korunmasına yönelik çalışmalara katkı sunacağı düşünülmektedir.

\section{Materyal ve Metot}

Bu çalışmada, materyal olarak kullanılan Nagami çeşidi kamkat meyveleri, Antalya ilinde üretim yapan bir üretici bahçesinden temin edilmiştir. Denemeler; Tokat Gaziosmanpaşa Üniversitesi, Ziraat Fakültesi Biyosistem Mühendisliği Bölümü Biyolojik Malzeme Laboratuvarında, biyoaktif özelliklerle ilgili analizler ise Bahçe Bitkileri Bioaktif Moleküller Laboratuvarında yapılmıştır. Meyve örneklerinin nem içeriklerinin tayini, etüvde $105 \pm 1^{\circ} \mathrm{C}$ sıcaklıkta 24 saat kurutularak ve yaş baz referans alınarak hesaplanmıştır Çalışmada kullanılan meyvelerin nem içeriği yaş baza göre 81.01 (\% y.b.) olarak belirlenmiştir (Suthar ve Das, 1996) (Şekil 1).
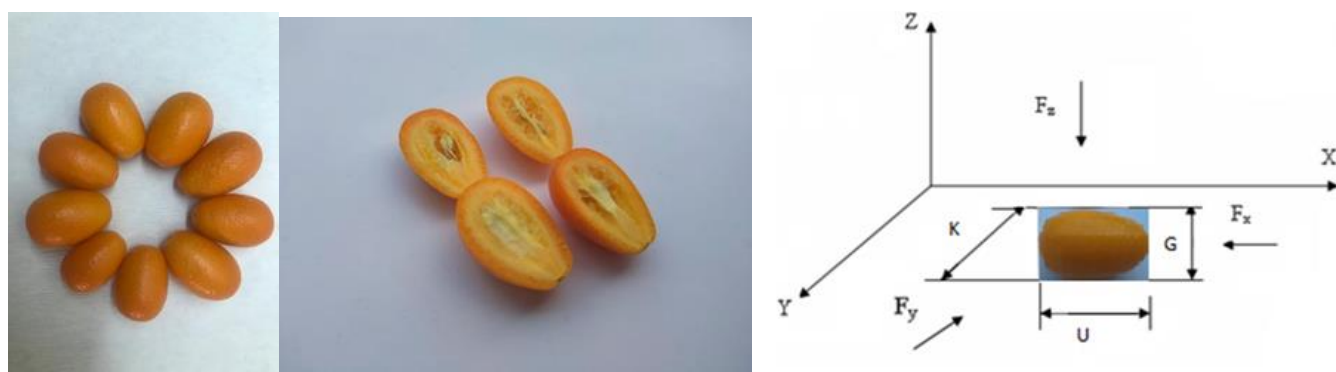

Şekil 1. Nagami kamkat meyve örnekleri ve örnek bir kamkat meyvesinin eksenel boyutlara ait $\left(F_{x}, F_{y}, F_{z}\right)$ kuvvetlerinin gösterimi.

Meyvelerin biyoteknolojik özellikleri içerisinde geometrik ve hacimsel özellikleri kapsamında boyut özellikleri, 0,01 mm hassasiyetli dijital kumpasla yapılmıştır. Meyve ağırıkları 0.001 gram hassasiyetli KERN marka EW620-3NM model hassas terazi ile belirlenmiştir. Meyve şekil indeksi $\left(M_{s ̧ i}\right)$, meyve uzunluğunun meyve genişliğine oranlanmasıyla belirlenmiştir (Kassem ve ark., 2011). Meyvelerin geometrik ortalama çap $\left(G_{\zeta}\right)$ $(\mathrm{mm})$, küresellik $\left(K_{r}\right)(\%)$, yüzey alanı $\left(Y_{a}\right)\left(\mathrm{mm}^{2}\right)$ ve 
hacim $\left(H_{t}\right) \quad\left(\mathrm{mm}^{3}\right)$ hesaplamaları için aşağıdaki eşitliklerden yararlanılmıştır (Mohsenin, 1980).

$G_{c}=(u g k)^{1 / 3}$

$Y_{a}=\pi\left(G_{c}\right)^{2}$

$K_{r}=\left(G_{c} / u\right) 100$

$H_{t}=\pi / 6$ (ug k)

Burada; $u$ : Uzunluk (mm), $g$ : Genişlik $(\mathrm{mm}), k$ : Kalınlık (mm), Gç: Geometrik ortalama çap $(\mathrm{mm})$, $Y_{a}$ : Yüzey alanı $\left(\mathrm{mm}^{2}\right)$ ve $K_{r}$ : Küresellik $(\%)^{\prime}$ dir.

Meyvelerin gerçek hacim ağırlığının $\left(H_{g},(\mathrm{~kg}\right.$ $\left.\mathrm{m}^{-3}\right)$ ) belirlenmesinde sıvı yer değiştirme metodu kullanılmış; akışkan sıvı olarak meyvelerde suya göre daha az absorbe özelliğine sahip olan Toluen sıvısı kullanılmıştır (Saçılık ve ark., 2003). Yığın hacim ağırlığı $\left(H_{y}\right)\left(\mathrm{kg} \mathrm{m}^{-3}\right)$ için hektolitre yöntemi uygulanmıştır. Porozite (boşluk oranı) değeri $\left(P_{r}\right)$, yığın hacim ağırlığı ve gerçek hacim ağırlığı değerleri de göz önüne alınarak Mohsenin (1980)'e göre belirlenmiştir.

Meyvelerin mekanik özellikleri kapsamında, farklı sürtünme yüzeylerindeki (galvanizli sac, PVC, kontrplak, laminant ve lastik) statik sürtünme katsayıları ölçümleri için sürtünme ölçüm düzeni kullanılmıştır. Sürtünme katsayısı, bir kol ile eğimlendirilen yüzeyden meyvelerin hareketine izin verilen düzenekteki eğim ( $\alpha$ ) açısına bağlı $\mu=\tan \alpha$ eşitliğinden hesaplanmıştır (Yılmaz ve Altuntas, 2020).

Meyvelerin mekanik kuvvet karşısındaki davranışları için delme testlerinde çeki bası dinamometresi, ölçüm standı, motorlu bir hareket ünitesi ve bir bilgisayar bağlantılı Sundoo HP-500 Biyolojik Materyal test cihazı (çeki bası dinamometresi, ölçüm standı, motorlu bir hareket ünitesi ve bir bilgisayar bağlantılı) kullanılmıştır. Testlerde, meyvelerin hem kuvvet ve hem de deformasyon aralıkları belirlenmiş, kuvvet ve zaman eğrisi grafik olarak da alınabilmektedir. Deformasyon ise test cihazına ekli ölçüm standından milimetrik olarak belirlenmiştir. Delme testlerinde, $11.1 \mathrm{~mm}$ çaplı silindirik bir uç kullanılarak, dört farklı yükleme hızı $\left(20 \mathrm{~mm} \mathrm{~min}^{-1}\right.$,

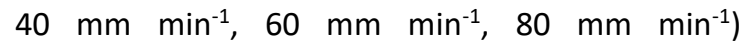
kullanılmıştır. Çalışmada, absorbe edilen enerji $(E)$, sertlik $(S)$ ve delme için gerekli güç $(G)$ aşağıdaki eşitlikler yardımıyla belirlenmiştir (Mohsenin, 1980).

$$
\begin{aligned}
& E=(F D) / 2 \\
& S=F / D, \\
& G=\left[\frac{E H}{60000 D}\right]
\end{aligned}
$$

Burada; $E$ : Absorbe edilen enerjisi ( $\mathrm{N} \mathrm{mm}), F$ : Delme kuvveti (N), D: Deformasyon ( $\mathrm{mm})$, S: Sertlik $\left(\mathrm{N} \mathrm{mm} \mathrm{m}^{-1}\right.$ ) ve $\mathrm{G}$ : Delme için gerekli olan güç $(\mathrm{W})$ değeridir.
Meyvelerin renk özelliklerini belirlemek amacıyla Minolta, model CR-400 (Tokyo, Japonya) renk cihazı kullanılarak meyve kabuk yüzeyi ve meyve eti $L^{*}, a^{*}$ ve $b^{*}$ renk ölçümleri yapılmıştır (McGuire, 1992). Kroma değeri $(C)$, meyvenin canlı ya da pastel tonunu göstermekte olup pastel tonlar 0 'a, canlı tonlar ise 100 'e yakın olarak tanımlanmaktadır (Günaydın, 2020). Kroma ve hue açısı ( $\alpha$ ) Eşitlik 9 ve 10’a göre hesaplanmıştır.

$C=\left(a^{2}+b^{2}\right)^{1 / 2}$
$h^{\circ}=\tan ^{-1}(b / a)$

Suda çözünür kuru madde miktarı (SÇKM), $\mathrm{pH}$ ve titre edilebilir asitliği (TA) belirlemek için kamkat meyveleri blenderda çekilmiştir. SÇKM, dijital refraktometre (PAL-1, Atago) ile ölçülüp, yüzde olarak ifade edilmiştir. pH ve TA ölçümleri için kamkat meyvelerinden $5 \mathrm{~g}$ tartılıp üzerine 95 $\mathrm{ml}$ saf eklenerek $100 \mathrm{~g}$ 'a tamamlanmıştır. $\mathrm{pH}$ için pH metre (HI9321; Hanna Instruments, Padova, İtalya) kullanılmıştır. Titre edilebilir asitlik, $0.1 \mathrm{~N}$ sodyum hidroksit $(\mathrm{NaOH})$ ile $\mathrm{pH}$ 8.1'e titre edilerek edilerek \% sitrik asit cinsinden ifade edilmiştir. C vitamini içeriği için yeterli miktarda meyve suyu alındıktan sonra askorbik asit test şeridi meyve suyuna daldırılmıştır ve reflektometre seti (Merck RQflex plus 10) başlatılmıştır. 2 saniye bekletilen test şeridi daha sonra üstündeki fazla sıvıyı çıkarmak için çalkalanarak 8 saniye bekletilip 15 . saniye sonuna kadar okuma yapılmıştır ve elde edilen değer $\mathrm{mg} \mathrm{L}^{-1}$ olarak ifade edilmiştir. Kamkat meyvelerinin toplam fenolik madde içeriği, Singleton ve Rossi (1965)'e göre belirlenmiştir. Bu doğrultuda, 2 g meyve pulpu tartılıp üzerine $18 \mathrm{ml}$ aseton, su ve asetik asit tampon çözeltisi eklenerek karanlık ortamda 24 saat etkileşime bırakılmıştır (70:29.5:0.5 $\mathrm{h} \mathrm{h}^{-1}$ ). Daha sonra $0.5 \mathrm{ml}$ ekstraktın üzerine $0.5 \mathrm{ml}$ Folin-Ciocalteu fenol renk ayıracı, 9 $\mathrm{ml}$ saf su ve 8 dakika sonra \%7 sodyum karbonat eklenerek inkübe edilmiştir. iki saatlik süre sonunda UV-VIS spektrofotometre (Model T60U, PG Instruments) ile $750 \mathrm{~nm}$ 'de absorbans otomatik olarak ölçülmüştür. Standart olarak gallik asit kullanılmıştır. Sonuçlar birim taze ağırlıkta $\mu$ g gallik

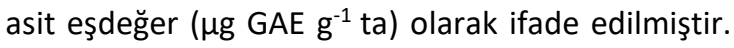
Standart Trolox eşdeğer antioksidan kapasitesi (TEAC) tayini için ABTS (2.2-azino-bis-3ethylbenzothiazoline-6-sulfonic acid) asetat tamponda çözündürülerek, Özgen ve ark. (2006)'a göre potasyum persülfat hazırlanmıştır. Karışımın stabilitesinin uzun süre olması için $20 \mathrm{mM}$ sodyum asetat tampon çözeltisinin asidik ortamında $(\mathrm{pH}=4.5), 734 \mathrm{~nm}$ 'de 0.700 absorbans gösterecek şekilde seyreltilmiştir. Spektrofotometrik ölçüm için $2.97 \mathrm{ml} \mathrm{ABTS}{ }^{+}$solusyonuna $30 \mu \mathrm{l}$ pulpsuz meyve suyu (santrifüj sonucu elde edilmiştir) ilave edilen çözelti 10 dakika boyunca inkübeye 
bırakılmış daha sonra $734 \mathrm{~nm}$ 'de absorbans okunmuştur. Elde edilen değerler gram taze ağırlıkta $\mu \mathrm{mol}$ TE olarak ( $\mu \mathrm{mol}$ TE $\mathrm{g}^{-1}$ ta) sunulmuştur. Toplam flavonoid miktarı tayini, Zhishen ve ark., (1999)'na göre belirlenmiştir. $1 \mathrm{~mL}$ meyve suyu, saf su ile $6 \mathrm{~mL}^{\prime} y e$ tamamlanıp üzerine $0.3 \mathrm{~mL} \% 5$ 'lik $\mathrm{NaNO}_{2}$ ilave edilmiştir. 5 dakika sonra $0.3 \mathrm{~mL} \% 10$ 'luk $\mathrm{AlCl}_{3}$ karışıma eklenerek yine 5 dakika sonra $2 \mathrm{~mL} 1 \mathrm{M} \mathrm{NaOH}$ eklenip 1 dakika sonra toplam hacim saf su ile $10 \mathrm{~mL}^{\prime} y e$ tamamlanmıştır. Hemen ardına absorbans değerleri, $510 \mathrm{~nm}$ 'de okunmuştur. Sonuçlar litre taze ağırlıkta mg kateşin eşdeğer olarak (mg KE L-1 ta) verilmiştir.

Araştırma sonuçlarının istatistiksel değerlendirmelerinde; SPSS (Statistical Package for Social Sciences) istatistik paket programı (SPSS 17) kullanılmıştır. Genel istatistik hesaplamalar dışında, mekanik davranışın belirlendiği kuvvet, deformasyon, sertlik ve sıkıştırma gücü parametrelerinde yükleme hızı ve eksenleri de kullanıldığı için varyans analizi yapılmıştır. Incelenen parametrelerle ilgili farklılıkların belirlenmesi amacıyla çoklu karşılaştırma (Duncan) testi de uygulanmıştır.

\section{Bulgular ve Tartışma \\ Fiziksel özellikler}

Nagami çeşit kamkat meyvelerine ait örneklerin biyoteknolojik özellikleri kapsamında fiziksel özelliklerden geometrik ve hacimsel özellikleri olarak boyutsal özellikleri, geometrik ortalama çap, küresellik, yüzey alanı değerleri ile meyve ağırlığı, yığın hacim ağırlığı ve meyve hacim ağırlığı değerleri belirlenmiştir. Meyvelerin geometrik ve hacimsel özellikleri Çizelge 1'de verilmiştir. Kamkat meyvesinin uzunluk, genişlik, kalınlık değerleri sırasıyla $33.76 \mathrm{~mm}, 23.24 \mathrm{~mm}$, $22.77 \mathrm{~mm}$ olarak belirlenmiştir. Meyvelerin geometrik ortalama çap, küresellik ve yüzey alanı değerleri sırasıyla $26.04 \mathrm{~mm}$ \%77.32 ve 2141.94 $\mathrm{mm}^{2}$ olarak belirlenmiştir. Meyve ağırlığı ortalama 10.64 g, yığın hacim ağırlığı ve meyve hacim ağırlığı değerleri ise, sırasıyla $551.34 \mathrm{~kg} \mathrm{~m}^{-3}$ ve 1083.60 $\mathrm{kg} \mathrm{m}^{-3}$ olarak belirlenmiştir.

Jaliliantabar ve ark. (2013), kamkat meyvesinde uzunluk genişlik, kalınlık, geometrik ortalama çap, küresellik, yüzey alanı ve şekil indeksi değerlerini sırası ile $39.5 \mathrm{~mm}, 25.7 \mathrm{~mm}$, $25.1 \mathrm{~mm}, 29.4 \mathrm{~mm}, \% 74.5,2743.0 \mathrm{~mm}^{2}, 1.6$ olarak bildirmiştir. Yıldız Turgut ve ark. (2015), kamkat meyve boyunu ve çapını sırasıyla $38.5 \mathrm{~mm}$ ve 26.9 $\mathrm{mm}$ olarak belirlemiştir. Kabaş (2010), İnterdonate limonun uzunluğunu 72.16-89.65 mm, çapını $60.18-71.40 \mathrm{~mm}$, geometrik ortalama çapını 63.25$70.64 \mathrm{~mm}$; Red blush altıntopunun uzunluğunu 70.66-86.21 mm, çapını 82.26-107.53 mm, geometrik ortalama çapını 70.16-92.87 mm, Satsuma mandarininin uzunluğunu 38.83-52.71 $\mathrm{mm}$, çapını 51.37-68.44 mm, geometrik ortalama çapını 43.52-54.92 mm olarak bildirmiştir. Literatür sonuçlarına göre, çalışmada kamkat meyvelerinin geometrik özelliklerinden uzunluk ve genişlik değerlerinin Jaliliantabar ve ark. (2013) ve Yıldız Turgut ve ark. (2015)'nın sonuçları ile benzerlik gösterdiği söylenebilir. Kabaş (2010)'ın bildirdiği turunçgil meyvelerine göre kamkat meyvelerinin daha düşük boyutlara sahip olduğu görülmektedir.

Çizelge 1. Kamkat meyvelerine ait bazı geometrik ve hacimsel özellikler

\begin{tabular}{|c|c|c|c|c|c|c|}
\hline Özellikler & & Ortalama $(*)$ & Maksimum & Minimum & $\begin{array}{l}\text { Varyasyon } \\
\text { katsayısı }\end{array}$ & $\begin{array}{l}\text { Standart } \\
\text { hata }\end{array}$ \\
\hline \multirow{7}{*}{ Geometrik } & $U(\mathrm{~mm})$ & $33.76 \pm 1.28$ & 35.78 & 31.21 & 3.79 & 0.41 \\
\hline & $G(\mathrm{~mm})$ & $23.24 \pm 0.82$ & 24.10 & 21.87 & 3.55 & 0.26 \\
\hline & $K(m m)$ & $22.77 \pm 0.86$ & 23.70 & 21.38 & 3.79 & 0.27 \\
\hline & $G c ̧(m m)$ & $26.04 \pm 0.93$ & 27.02 & 24.33 & 3.57 & 0.29 \\
\hline & $K r(\%)$ & $77.32 \pm 1.11$ & 78.61 & 75.46 & 1.44 & 0.35 \\
\hline & $Y a\left(m m^{2}\right)$ & $2141.94 \pm 143.60$ & 2298.86 & 1890.60 & 6.70 & 45.44 \\
\hline & Mşi & $1.46 \pm 0.03$ & 1.51 & 1.42 & 2.01 & 0.01 \\
\hline \multirow{5}{*}{ Hacimsel } & $A(g)$ & $10.64 \pm 1.08$ & 11.70 & 8.80 & 10.12 & 0.34 \\
\hline & $H_{t}\left(m m^{3}\right)$ & $9485.61 \pm 899.82$ & 10501.18 & 7983.18 & 9.49 & 284.75 \\
\hline & $H_{y}\left(\mathrm{~kg} \mathrm{~m}^{-3}\right)$ & $551.34 \pm 16.31$ & 569.75 & 532.31 & 2.96 & 7.28 \\
\hline & $H_{g}\left(\mathrm{~kg} \mathrm{~m}^{-3}\right)$ & $1083.60 \pm 48.54$ & 1143.58 & 1010.10 & 4.48 & 21.67 \\
\hline & $P_{r}(\%)$ & $49.08 \pm 1.32$ & 50.52 & 47.30 & 2.68 & 0.59 \\
\hline
\end{tabular}

U: Uzunluk (mm), G: Genişlik $(\mathrm{mm})$ K: Kalınlık $(\mathrm{mm})$, Gç: Geometrik ortalama çap $(\mathrm{mm})$, Kr: Küresellik (\%), Ya: Yüzey Alanı $\left(\mathrm{mm}^{2}\right)$, Mşi: Meyve Şekil indeksi, A: Tek tane ağırık $(\mathrm{g}), \mathrm{Ht}$ : Hacim $\left(\mathrm{mm}^{3}\right), \mathrm{Hy}$ : Yığın hacim ağırlığı $\left(\mathrm{kg} \mathrm{m}^{-3}\right), \mathrm{Hg}: \mathrm{Meyve}$ hacim ağırlığı $\left(\mathrm{kg} \mathrm{m}^{-3}\right)$, Pr: Porozite $(\%)(*): \pm$ değerler standart sapmayı göstermektedir.

Jaliliantabar ve ark. (2013), kamkat meyvesinde ağırlık değerini $14.3 \mathrm{~g}$ ve porozite değerini 63.8 \% olarak belirlerken; Yıldız Turgut ve ark. (2015), kamkat meyve ağırığını 13.67 g; Uslu
(2015) ise $11.38 \mathrm{~g}$ olarak açıklamıştır. Kabaş (2010); Interdonate limonun ağırlığının 109.41$165.37 \mathrm{~g}$, Red blush altıntopun ağırlığının 206.87$400.45 \mathrm{~g}$, Satsuma mandarininin ağırlığının 63.58- 
79.80 g olduğunu bildirmişlerdir. Literatür sonuçlarına göre, çalışmada kamkat meyvelerinin ağırlık değerleri Uslu (2015)'nun sonuçları ile benzerlik gösterirken, Jaliliantabar ve ark. (2013) ve Yıldız Turgut ve ark. (2015)'nın belirttiği değerlerden daha düşük bulunmuştur. Kabaş (2010)'ın bildirdiğine göre, kamkat meyve ağırlıklarının portakal, limon, altıntop ve mandarine nazaran daha düşük olduğu görülmektedir.

\section{Renk Özellikleri}

Kamkat meyvelerinin kabuk yüzeyi ve meyve eti üzerinden ölçülen renk özelliklerine ait değerler $\left(L^{*}, a^{*}, b^{*}\right.$, kroma, hue açısı) Çizelge $2^{\prime}$ de verilmiştir. $L^{*}, a^{*}, b^{*}$ renk değerleri hasat sonrasındaki taze meyvelerin kabuk yüzeyi için sırası ile 59.89, 23.38 ve 54.86 olarak belirlenirken, meyve eti için bu değerler sırasıyla 60.01, 5.43 ve 34.00 olarak belirlenmiştir. Küçük ve Doymaz (2019), taze kamkat dilimlerinin renk parametreleri için ortalama değerleri için $L^{*}$ değerinin $60.49, a^{*}$ değerinin 22.24 ve $b^{*}$ değerini ise 51.88 olarak bulunduğunu açıklamışlardır. Literatür sonuçlarına göre, çalışmada kamkat meyvelerinin $L^{*}, a^{*}, b^{*}$ değerleri Küçük ve Doymaz (2019)'in belirttiği sonuçlarla benzerlik gösterdiği görülmektedir.

Çizelge 2. Kamkat meyvelerine ait meyve kabuk yüzeyi ve meyve etinin renk karakteristikleri

\begin{tabular}{ccccccc}
\hline Meyve yüzeyi & $\begin{array}{c}\text { Renk } \\
\text { karakteristikleri }\end{array}$ & Ortalama $\left(^{*}\right)$ & Maksimum & Minimum & $\begin{array}{c}\text { Varyasyon } \\
\text { katsayısı }\end{array}$ & $\begin{array}{c}\text { Standart } \\
\text { hata }\end{array}$ \\
\hline \multirow{2}{*}{ Meyve } & $\boldsymbol{L}^{*}$ & $59.89 \pm 1.32$ & 62.54 & 58.14 & 2.20 & 0.42 \\
kabuğu & $\boldsymbol{a}^{*}$ & $23.38 \pm 1.98$ & 25.70 & 19.18 & 8.46 & 0.63 \\
& $\boldsymbol{b}^{*}$ & $54.86 \pm 1.34$ & 57.29 & 52.71 & 2.44 & 0.42 \\
& $\boldsymbol{C}$ & $59.65 \pm 1.74$ & 62.67 & 56.86 & 2.92 & 0.55 \\
& $\boldsymbol{h}^{\circ}$ & $66.94 \pm 1.58$ & 70.29 & 65.25 & 2.37 & 0.50 \\
\hline \multirow{2}{*}{ Meyve } & $\boldsymbol{L}^{*}$ & $60.01 \pm 2.72$ & 64.51 & 56.08 & 4.54 & 0.86 \\
eti & $\boldsymbol{a}^{*}$ & $5.43 \pm 2.28$ & 8.20 & 1.47 & 42.03 & 0.72 \\
& $\boldsymbol{b}^{*}$ & $34.00 \pm 7.21$ & 42.43 & 19.63 & 21.19 & 2.28 \\
& $\boldsymbol{C}$ & $34.46 \pm 7.39$ & 43.22 & 19.85 & 21.44 & 2.34 \\
\hline $\boldsymbol{h}^{\circ}$ & $81.17 \pm 2.80$ & 86.97 & 77.25 & 3.45 & 0.88 \\
\hline
\end{tabular}

$\left({ }^{*}\right): \pm$ değerler standart sapmayı göstermektedir.

\section{Mekanik Özellikler}

Kamkat meyvelerinin statik sürtünme katsayısı değerleri Çizelge 3'te; farklı yükleme hızları ve yükleme eksenlerindeki (uzunluk $X$-, genişlik $Y$-, kalınlık Z-) delme kuvveti, deformasyon, absorbe edilen enerji, sertlik ve delme için gerekli güç değerleri ise Çizelge 4'te verilmiştir. Topuz ve ark. (2005), dört farklı portakal çeşidinde lastik, kontrplak ve galvanizli sac yüzeyde statik sürtünme katsayısı değerlerini Alanya çeşidi için sırasıyla $0.270,0.258,0.247$; Finike çeşidi için sırasıyla $0.200,0.187,0.175 ;$ W. Navel çeşidi için sırasıyla $0.175,0.162,0.147$; Shamouti çeşidi için sırasıyla $0.124, \quad 0.107,0.113$ olarak açıklamışlardır. Baradaran Motie ve ark. (2014), iki farklı limon çeşidinde lastik ve galvanizli sac yüzeyde statik sürtünme katsayısı değerlerini Seedless Lisbon çeşidi için sırasıyla 0.252, 0.243; Frost Eureka çeşidinde ise $0.278,0.268$ olarak ifade etmişlerdir. Veeravenkatesh ve Vishnuvardhan (2014), üç farklı boyutta sınıflandırılmış portakal meyvesinde kontrplak yüzeyde statik sürtünme katsayısı değerlerini küçük meyvelerde 0.22 , orta boyut meyvelerde 0.18 ve büyük meyvelerde ise 0.23 olarak açıklamışlardır. Literatür sonuçlarına göre, çalışmada kamkat meyvelerinin statik sürtünme katsayısı değerleri Topuz ve ark. (2005), Baradaran Motie ve ark. (2014) ve Veeravenkatesh ve
Vishnuvardhan (2014) tarafından belirtilen sürtünme katsayısı değerlerinden daha yüksek bulunmuştur.

Çizelge 4'e göre, kamkat meyvelerine ait kuvvet, deformasyon, absorbe edilen enerji, sertlik ve sıkıştırma gücü değerlerinin farklı yükleme hızları ve yükleme eksenlerine göre değişimleri kamkat meyvelerinde en yüksek kuvvet değeri 80

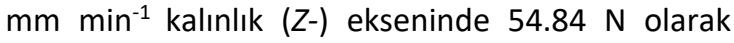
ölçülmüştür. En yüksek sertlik değeri, $40 \mathrm{~mm} \mathrm{~min}^{-1}$ yükleme hızında genişlik ( $Y$-) ekseninde $5.24 \mathrm{~N} \mathrm{~mm}^{-}$ ${ }^{1}$ ile bulunmuştur. Altuntas ve ark. (2013), muşmula meyvelerinin sabit $1.06 \mathrm{~mm} \mathrm{~s}^{-1}\left(31.8 \mathrm{~mm} \mathrm{~min}^{-1}\right.$ ) yükleme hızında ve $7.9 \mathrm{~mm}$ çaplı silindirik uç kullanılarak delme testinde $X$ - ekseni boyunca delme kuvveti ve absorbe edilen enerji değerlerinin fizyolojik olgunluktan olgunlaşma dönemine kadar sırasıyla $82.3 \mathrm{~N}$ ile $8.1 \mathrm{~N}$ (\%90.2 azalma) ve $593.6 \mathrm{~N}$ ile $74.0 \mathrm{~N} \mathrm{~mm} \mathrm{( \% 87.5} \mathrm{azalma)} \mathrm{arasında} \mathrm{değiştiğini}$ açıklamışlardır. Fizyolojik olgunluktan olgunlaşma dönemine 1.9 mm çaplı iğne uç kullanılarak delme testinde ise, muşmula meyvelerinin delme kuvveti ve delme için gerekli absorbe edilen enerji değerlerini ise sırasıyla 17.4 ile $1.20 \mathrm{~N}$ (\%93.1 azalma) ve 127.9 ile $12.6 \mathrm{~N} \mathrm{~mm} \mathrm{( \% 90.1} \mathrm{azalma)}$ olarak bulmuşlardır. Muşmula meyvelerinin deformasyon değerlerinin ise fizyolojik olgunluktan olgunlaşma dönemine kadar sırasıyla 14.4 mm'den 
18.3 mm'ye (silindirik uç ile) ve 15.6'dan 20.1 mm'ye (iğneli uç ile) yükseldiğini açıklamışlardır. Bu durumun daha yüksek meyve olgunluğu oranının ve muşmula meyvelerinin sertliğinin azalmasının bir sonucu olduğunu ifade etmişlerdir.

Çalışmada, kamkat için $11.1 \mathrm{~mm}$ çaplı silindirik uç ile yapılan delme testlerinde, $20 \mathrm{~mm}$ $\mathrm{min}^{-1}$ ile $40 \mathrm{~mm} \mathrm{~min}^{-1}$ yükleme hızları için $X$ - ekseni boyunca delme kuvveti değerleri $28.78 \mathrm{~N}$ ile 38.24 $\mathrm{N}$ olarak, deformasyon değerleri $9.83 \mathrm{~mm}$ ile 12.37 $\mathrm{mm}$ olarak ve absorbe edilen enerji değerleri de $141.46 \mathrm{~N} \mathrm{~mm}$ ile $210.33 \mathrm{~N} \mathrm{~mm}$ olarak bulunmuştur. Buna göre, kamkatın delme kuvveti, deformasyon ve absorbe edilen enerji değerleri, muşmula meyvesinin fizyolojik olgunluk dönemi değerlerinden daha yüksek bulunmuştur.

Çizelge 3. Kamkat meyvelerine ait statik sürtünme katsayısı değerleri.

\begin{tabular}{lccccc}
\hline \multicolumn{7}{l}{ Sürtünme katsayısı } & & & \\
\hline $\begin{array}{l}\text { Sürtünme } \\
\text { yüzeyi }\end{array}$ & Ortalama $\left.{ }^{*}\right)$ & Maksimum & Minimum & $\begin{array}{c}\text { Varyasyon } \\
\text { katsayısı }\end{array}$ & $\begin{array}{c}\text { Standart } \\
\text { hata }\end{array}$ \\
\hline PVC & $0.306 \pm 0.016$ & 0.325 & 0.287 & 5.096 & 0.005 \\
Galvanizli sac & $0.276 \pm 0.024$ & 0.306 & 0.231 & 8.600 & 0.007 \\
Laminant & $0.257 \pm 0.013$ & 0.268 & 0.231 & 5.056 & 0.004 \\
Kontrplak & $0.329 \pm 0.018$ & 0.344 & 0.306 & 5.395 & 0.006 \\
Lastik & $0.368 \pm 0.021$ & 0.404 & 0.344 & 5.570 & 0.006 \\
\hline
\end{tabular}

PVC: Polivinil Klorür, $\left({ }^{*}\right): \pm$ değerler standart sapmayı göstermektedir.

Çizelge 4. Kamkat meyvelerine ait delme testleri sonucu elde edilen kuvvet, deformasyon, absorbe edilen enerji, sertlik ve delme için gerekli güç değerlerinin farklı yükleme hızları ve yükleme eksenlerine göre değişimleri

\begin{tabular}{|c|c|c|c|c|c|c|}
\hline $\begin{array}{l}\text { Yükleme } \\
\text { hızları } \\
\text { (mm } \\
\left.\text { min }^{-1}\right)\end{array}$ & $\begin{array}{l}\text { Yükleme } \\
\text { ekseni }\end{array}$ & $\begin{array}{l}\text { Kuvvet } \\
\text { (N) }\end{array}$ & $\begin{array}{l}\text { Deformasyon } \\
(\mathrm{mm})\end{array}$ & $\begin{array}{l}\text { Absorbe edilen } \\
\text { enerji } \\
\text { ( } \mathrm{N} \mathrm{mm} \text { ) }\end{array}$ & $\begin{array}{l}\text { Sertlik } \\
\left(\mathrm{N} \mathrm{mm}^{-1}\right)\end{array}$ & $\begin{array}{l}\text { Delme için gerekli } \\
\text { güç (W) }\end{array}$ \\
\hline \multirow{4}{*}{20} & $x-$ & $28.78 \pm 3.98 b^{* *}$ & $9.83^{n s} \pm 1.56$ & $141.46 \pm 30.07 \mathrm{~b} * *$ & $3.00 \pm 0.71 b^{* *}$ & $0.0048 \pm 0.0007 b^{* *}$ \\
\hline & $Y-$ & $44.13 \pm 6.79 a * *$ & $11.50^{\text {ns }} \pm 1.63$ & $252.41 \pm 43.24 a * *$ & $3.91 \pm 0.84 a * *$ & $0.0074 \pm 0.0011 a * *$ \\
\hline & $Z-$ & $47.51 \pm 4.02 \mathrm{a} * *$ & $10.61^{\text {ns }} \pm 0.78$ & $252.24 \pm 31.25 \mathrm{a} * *$ & $4.50 \pm 0.47 a * *$ & $0.0079 \pm 0.0007 a * *$ \\
\hline & F değeri & 30.62 & 2.94 & 26.21 & 9.52 & 30.62 \\
\hline \multirow{4}{*}{40} & $x-$ & $34.24 \pm 5.30 b^{* *}$ & $12.37 \pm 2.23 a^{* *}$ & $210.33 \pm 40.15 b^{* *}$ & $2.86 \pm 0.71 b^{* *}$ & $0.0114 \pm 0.0018 b^{* *}$ \\
\hline & $Y-$ & $51.98 \pm 0.64 a * *$ & $9.99 \pm 0.95 b^{* *}$ & $259.71 \pm 24.66 a * *$ & $5.24 \pm 0.53 a * *$ & $0.0173 \pm 0.0002 a * *$ \\
\hline & $Z-$ & $50.84 \pm 3.84 a * *$ & $10.18 \pm 1.07 b^{* *}$ & $258.46 \pm 30.82 a * *$ & $5.05 \pm 0.75 a * *$ & $0.0169 \pm 0.0013 a * *$ \\
\hline & F değeri & 54.70 & 5.96 & 6.00 & 31.37 & 54.70 \\
\hline \multirow{4}{*}{60} & $x-$ & $36.40 \pm 3.46 b^{* *}$ & $11.30 \pm 1.16^{\mathrm{ns}}$ & $206.07 \pm 32.96 b^{* *}$ & $3.24 \pm 0.38 b^{* *}$ & $0.0182 \pm 0.0017 b^{* *}$ \\
\hline & $Y-$ & $52.75 \pm 2.68 a * *$ & $10.73 \pm 1.41^{\mathrm{ns}}$ & $282.27 \pm 35.66 \mathrm{a} * *$ & $5.01 \pm 0.86 a * *$ & $0.0264 \pm 0.0013 a * *$ \\
\hline & $Z-$ & $53.63 \pm 1.25 a * *$ & $10.82 \pm 1.27^{\mathrm{ns}}$ & $290.04 \pm 34.66 a * *$ & $5.01 \pm 0.54 a * *$ & $0.0268 \pm 0.0006 a * *$ \\
\hline & F değeri & 109.14 & 0.46 & 14.52 & 21.41 & 109.14 \\
\hline \multirow{4}{*}{80} & $x-$ & $39.61 \pm 4.64 b^{* *}$ & $15.88 \pm 3.59 a * *$ & $314.18 \pm 80.20^{\text {ns }}$ & $2.61 \pm 0.69 b^{* *}$ & $0.0264 \pm 0.0031 b^{* *}$ \\
\hline & $Y-$ & $52.99 \pm 2.27 a * *$ & $11.36 \pm 2.23 b^{* *}$ & $299.68 \pm 50.59^{n s}$ & $4.81 \pm 0.89 a * *$ & $0.0353 \pm 0.0015 a * *$ \\
\hline & $Z-$ & $54.84 \pm 2.48 a * *$ & $11.47 \pm 1.60 b^{* *}$ & $313.79 \pm 41.28^{\mathrm{ns}}$ & $4.88 \pm 0.80 \mathrm{a} * *$ & $0.0366 \pm 0.0017 a * *$ \\
\hline & F değeri & 50.49 & 7.79 & 0.15 & 20.90 & 50.49 \\
\hline
\end{tabular}

**: $\mathrm{p}<0.01$, ns: önemsiz, \pm değerler standart sapmayı göstermektedir.

\section{Kimyasal Özellikler}

Kamkat meyvelerinin kimyasal özellikleri kapsamında suda çözünür kuru madde içeriği (SÇKM), pH ve titre edilebilir asitliği (TA) yanında, biyoaktif özelliklerden toplam fenolik, antioksidan kapasitesi, toplam flavonoid, $\mathrm{C}$ vitamini değerlerine ait sonuçlar, Çizelge 5'te verilmiştir. Çizelge 5'e bakıldığında ortalama $\mathrm{pH}$ değeri 3.35 , TA değeri \%1.47 ve SÇKM değeri \%12.93 olarak bulunmuştur. Babazadeh-Darjazi ve Jaimand, (2019) farklı turunçgil anaçlarında kamkat ağacının performansını araştırmışlardır. Çalışmada elde 
ettikleri $\mathrm{pH}$ değerleri; 2.2, 2.25 ve 2.43, TA değerleri; 3.44 , 3.39 ve 2.98 , SÇKM değerleri; 10.8 , 10.9 ve 11.06 olarak bulunmuştur. Chang ve Lin, (2020) sıcaklığın kamkat meyvesinin gelişimine ve kalite performanslarına etkisini araştırmışlardır. Meyve kabuğunda ve pulpunda yaptıkları analiz sonuçlarına göre: TA değeri meyve kabuğunda \%1.27, meyve pulpunda 3.88 SÇKM değeri ise meyve kabuğunda \%14.8, meyve pulpunda \%12.07 olarak elde edilmiştir. Ramful ve ark. (2011) kamkat meyvesini nisan ve haziran ayında hasat ederek meyve analizlerini yapmışlardır. Elde edilen TA değerleri aylara göre sırasıyla \%1.34, 1.83 ve SÇKM değerleri sırasıyla \%12.21 ve 13.12 olarak belirlenmiştir. Bulunan sonuçlarla yaptığımız çalışmada elde edilen veriler uyuşmaktadır.

Fitokimyasal özellikler incelendiğine (Çizelge 5), ortalama toplam fenolik madde değeri 116.19 $\mu \mathrm{g} \mathrm{GAE} \mathrm{g}{ }^{-1}$ ta, ortalama antioksidan kapasitesi 2.98 $\mu \mathrm{mol} \mathrm{TE} \mathrm{g}^{-1}$ ta, ortalama toplam flavonoid değeri $34.04 \mathrm{mg} \mathrm{KE} \mathrm{L}^{-1}$ ta ve ortalama $C$ vitamini değeri 308.67 mg/L olarak bulunmuştur. Keskin-Šašić ve ark. (2012)'nın meyve sularında toplam fenolik madde içeriği ve antioksidan kapasitelerinin belirlenmesi amacıyla yaptıkları çalışmada, kamkat meyvesinin toplam fenolik madde içeriğini santrifüj edilmiş örneklerde ve edilmemiş olanlarda sırasıyla 11.65 ve $15.02 \mathrm{mg}$ GAE $100 \mathrm{~mL}^{-1}$ ta bulmuşlardır. Yine aynı çalışmada meyve sularının antioksidan kapasitelerini ölçmek için oksijen radikal absorbans kapasitesi (ORAC) yöntemi kullanılmıştır. Elde edilen sonuçlar santrifüj edilmiş ve edilmemiş meyve suyu örneklerinde sırasıyla 133.50 ve 38.16 $\mu \mathrm{mol}$ TE $100 \mathrm{~mL}^{-1}$ ta bulunmuştur. Guo ve ark., (2003) farklı meyvelerin pulp, kabuk ve çekirdeklerinde antioksidan aktivitelerini ferrik indirgeme/antioksidan güç deneyi (FRAP deneyi)'ni uygulayarak belirlemişlerdir. Kamkat meyvesinin pulp, kabuk ve çekirdeklerinde elde ettikleri antioksidan aktivite değerleri sırasıyla $0.50,0.25$ ve $0.66 \mathrm{mmol} 100 \mathrm{~g}^{-1}$ ta olarak bulunmuştur. Ramful ve ark., (2011)'nın nisan ve haziran ayında hasat ettikleri kamkat meyvelerinin analiz sonuçlarına göre her iki dönemde de hasat edilen meyvelerde toplam fenolik madde içeriği> $950 \mu \mathrm{g} \mathrm{g}^{-1}$ ta ve toplam flavonoid madde içeriği $<400 \mu \mathrm{g} \mathrm{g}^{-1}$ ta olarak ifade edilmiş, $\mathrm{C}$ vitamini değerleri aylara göre sırasıyla> $500 \mu \mathrm{g} \mathrm{mL}$ ve $300-500 \mu \mathrm{g} \mathrm{mL}$ olarak belirlenmiş, TEAC ise sırasıyla 7.79 ve 9.92 $\mu \mathrm{mol}$ Trolox $\mathrm{g}^{-1}$ ta olarak elde edilmiştir. Wang ve ark. (2007) ve Vinci ve ark., (1995) kamkat meyvesinde yaptıkları çalışmada C vitamini değerlerini sırası ile $6.77 \mathrm{mg} \mathrm{g}^{-1}$ ve $55.29 \mathrm{mg} 100 \mathrm{~g}^{-1}$ olarak belirlemişlerdir. Genel olarak yaptığımız çalışma ile daha önce yapılan çalışmalar arasında oluşan uyuşmazlıklar, meyvelerin çeşit ve hasat zamanlarındaki farklılıklarından, uygulanan farklı analiz metotlarından ve meyvelerin yetiştiği ekolojik koşullardan kaynaklanıyor olabilir.

Çizelge 5. Kamkat meyvesinin bazı kimyasal özellikleri

\begin{tabular}{|c|c|c|c|c|c|}
\hline Kimyasal özellikler & Ortalama $(*)$ & Maksimum & Minimum & $\begin{array}{c}\text { Varyasyon } \\
\text { katsayısı }\end{array}$ & $\begin{array}{c}\text { Standart } \\
\text { hata }\end{array}$ \\
\hline$p H$ & $3.35 \pm 0.16$ & 3.52 & 3.20 & 4.80 & 0.09 \\
\hline TA (\%) & $1.47 \pm 0.02$ & 1.49 & 1.46 & 1.21 & 0.01 \\
\hline SÇKM (\%) & $12.93 \pm 0.23$ & 13.20 & 12.80 & 1.79 & 0.13 \\
\hline$T F e(\mu g G A E / g t a)$ & $116.19 \pm 2.40$ & 118.78 & 114.03 & 2.07 & 1.39 \\
\hline$T E A C(\mu \mathrm{mol} T E / g \mathrm{ta})$ & $2.98 \pm 0.04$ & 3.01 & 2.94 & 1.21 & 0.02 \\
\hline$T F I(m g K E / L t a)$ & $34.04 \pm 1.70$ & 35.89 & 32.56 & 4.99 & 0.98 \\
\hline C Vitamini(mg/L) & $308.67 \pm 6.11$ & 314.00 & 302.00 & 1.98 & 3.53 \\
\hline
\end{tabular}

TFe: Toplam fenolik ( $\mu \mathrm{g}$ GAE/g ta), TEAC: Trolox eşdeğer antioksidan kapasitesi ( $\mu \mathrm{mol}$ TE/g ta),TFI: Toplam Flavonoid (mg KE/L ta), C Vitamini (mg/L), TA: Titre edilebilir asitlik, SÇKM: Suda çözünür kuru madde, ta: taze ağırlık. $\left({ }^{*}\right): \pm$ değerler standart sapmayı göstermektedir.

\section{Sonuç ve Öneriler}

Araştırma kapsamında, Nagami kamkat çeşidinin biyoteknolojik karakteristiklerinden geometrik, hacimsel, renk, mekanik direnç özellikleri ve biyoaktif özelliklerden toplam fenolik, antioksidan kapasitesi, toplam flavonoid, C vitamini incelenmiştir. Boyut özelliklerden ortalama uzunluk, genişlik, kalınlık değerleri sırasıyla 33.76 $\mathrm{mm}, 23.24 \mathrm{~mm}$ ve $22.77 \mathrm{~mm}$ olarak belirlenmiştir. Ortalama ağırlık $10.64 \mathrm{~g}$ olarak belirlenmiştir. Ortalama yığın hacim ağırlığı, meyve hacim ağırlığı ve porozite değeri sırasıyla $551.34 \mathrm{~kg} \mathrm{~m}^{-3}, 1083.60$ $\mathrm{kg} \mathrm{m}^{-3}, \% 49.08$ olarak belirlenmiştir. En yüksek $L^{*}$ değeri meyve etinde gözlenirken, en yüksek $a^{*}$ değeri meyve kabuk yüzeyinde belirlenmiştir. Mekanik test sonuçlarına göre en yüksek delme 
kuvveti değeri $80 \mathrm{~mm} \mathrm{~min}^{-1}$ kalınlık (Z-) ekseninde $54.84 \mathrm{~N}$ ile belirlenirken, en yüksek sertlik değeri, $40 \mathrm{~mm} \min ^{-1}$ yükleme hızında genişlik ( $Y$-) ekseninde $5.24 \mathrm{~N} \mathrm{~mm}^{-1}$ ile belirlenmiştir. Ortalama $\mathrm{pH}$ değeri 3.35, TA değeri \%1.47 ve SÇKM değeri \%12.93 olarak belirlenmiştir. Ortalama toplam fenolik madde değeri $116.19 \mu \mathrm{g} \mathrm{GAE} / \mathrm{g}$ ta, ortalama antioksidan kapasitesi $2.98 \mu \mathrm{mol} \mathrm{TE} \mathrm{g}{ }^{-1}$ ta, ortalama toplam flavonoid değeri $34.04 \mathrm{mg} \mathrm{KE} \mathrm{L}^{-1}$ ta ve ortalama C vitamini değeri $308.67 \mathrm{mg} \mathrm{L}^{-1}$ olarak bulunmuştur. Kamkat meyvesinin hasat sonrasına yönelik biyoteknolojik özelliklerinin belirlenmesine ait verilerin hasat ve hasat sonrası teknoloji ve uygulamalarla ilgili tasarlanacak ve geliştirilecek alet, ekipman ve sistem donanımlarında dikkate alınmasına katkı sunacaktır. Ülkemizdeki gelişen önemi dikkate alındığında kamkat üretim alanlarının artmasına bağlı olarak da, taze ve sanayiye yönelik uygulamalarda ürünün temizlenmesi, boyutlarına göre sınıflandırılması, paketlenmesi ve ambalajlanmasında kullanılacak sistem ve tesislerin donanımlarındaki biyoteknoljik özelliklerine ait sonuçların, kamkatın hem hasat hem de hasat sonrası ürün kalitesi ile birlikte ticari olarak değerinin artırılmasına katkı sunabileceği düşünülmektedir.

Çıkar Çatışması Beyanı: Makale yazarları aralarında herhangi bir çıkar çatışması olmadığını beyan ederler.

Araştırmacıların Katkı Oranı Beyan Özeti: Yazarlar makaleye eşit oranda katkı sağlamış olduklarını beyan ederler.

\section{Kaynaklar}

Altuntas, E., Gul, E.N. ve Bayram, M. 2013. The physical, chemical and mechanical properties of medlar (Mespilus germanica L.) during physiological maturity and ripening period. Journal of Agricultural Faculty of Gaziosmanpasa University (JAFAG), 30 (1): 33-40.

Anonim (2016). https://arastirma.tarimorman.gov.tr/batem /Belgeler/Basin/kamkat.pdf (Erişim tarihi: 22.08.2021).

Anonim. 2021.

https://www.sozcu.com.tr/2020/ekonomi/p andemi-ile-talep-artti-kamkat-hasadibasladi-6176358/ Erişim tarihi: 25.04.2021.

Babazadeh-Darjazi, B. ve Jaimand, K. 2019. Physicochemical Characteristics of Kumquat (Fortunella margarita) on Citrus Rootstocks. Journal of Medicinal plants and By-product, 8(2), 105-114.
Baradaran Motie, J., Miraei Ashtiani, S.H., Abbaspour-Fard, M.H. ve Emadi, B. 2014. Modeling physical properties of lemon fruits for separation and classification. International Food Research Journal, 21(5): 1901-1909.

Chang, Y.C. ve Lin, T.C. 2020. Temperature Effects on Fruit Development and Quality Performance of Nagami Kumquat (Fortunella margarita [Lour.] Swingle). The Horticulture Journal, UTD-120.

Guo, C., Yang, J., Wei, J., Li, Y., Xu, J. ve Jiang, Y. 2003. Antioxidant activities of peel, pulp and seed fractions of common fruits as determined by FRAP assay. Nutrition research, 23(12), 1719-1726.

Günaydın, S. 2020. Mikrodalga, konvektif ve gölgede kurutma yöntemleri kullanılarak kurutulmuş kuşburnu meyvesinin kurutma kinetiği, renk ve besin elementi içeriği açısından incelenmesi. Yüksek lisans tezi. Bursa Uludağ Üniversitesi Fen Bilimleri Enstitüsü, 65 sayfa, Bursa.

Jaliliantabar F., Lorestani, A.N. ve Gholami, R. 2013. Physical properties of kumquat fruit. International Agrophysics, 27: 107-109.

Jarvis, B.J. 2017. Get acquainted with kumquat. Pasco County Cooperative Extension, Florida.

Kabaş, Ö. 2010. Bazı Turunçgil Meyvelerinin Fiziksel Özelliklerinin Belirlenmesi. Batı Akdeniz Tarımsal Araştırma Enstitüsü Derim Dergisi, 2010, 27(1):33-42.

Kassem, H.A., Al-Obeed, R.S., Ahmed, M.A. ve Omar, A.K.H. 2011. Productivity, fruit quality and profitability of Jujube Trees Improvement by Preharvest Application of Agro-Chemicals. Middle-East Journal of Scientific Research, 9 (5), 628-637.

Keskin-Šašić, I., Tahirović, I., Topčagić, A., Klepo, L., Salihović, M.B., Ibragić, S. ve Velispahić, E. 2012. Total phenolic content and antioxidant capacity of fruit juices. Bulletin of the Chemists and Technologists of Bosnia and Herzegovina, 39, 25-28.

Küçük i. ve Doymaz i. 2019. Experimental and Modeling Investigation of Mass Transfer during Infrared Drying of Kumquat Slices. Adıyaman University Journal of Science, 9 (1): 48-65.

McGuire, R.G. 1992. Reporting of Objective Colour Measurements. HortScience, 27 (12): 12541255.

Mohsenin, N.N. 1980. Physical properties of plant and animal materials. Gordon and Breach Science Publishers, New York, 758 p. 
Olcay, N., Demir, M.K. 2019. Kamkatın (Fortunella spp.) Besinsel İçeriği ve Fonksiyonel Özellikleri. Iğdır Üniversitesi Fen Bilimleri Enstitüsü Dergisi, 9(4): 2124-2132.

Ozgen, M., Reese, R.N., Tulio, A.Z., Scheerens, J.C. ve Miller, A.R. 2006. Modified 2, 2-azino-bis3-ethylbenzothiazoline-6-sulfonic acid (ABTS) method to measure antioxidant capacity of selected small fruits and comparison to ferric reducing antioxidant power (FRAP) and 2, 2 '-diphenyl-1picrylhydrazyl (DPPH) methods. Journal of Agricultural and Food Chemistry, 54(4), 1151-1157.

Saçılık, K., Öztürk, R. ve Keskin, R. 2003. Some physical properties of Hemp seed. Biosystems Engineering, 86 (2), 191-198.

Suthar, S.H., Das, S.K., 1996. Some physical properties of Karingda [Citrus lanatus (thumb) mansf] grains. Journal of Agricultural Engineering Research, 65: 1522.

Ramful, D., Tarnus, E., Aruoma, O.I., Bourdon, E. ve Bahorun, T. 2011. Polyphenol composition, vitamin $\mathrm{C}$ content and antioxidant capacity of Mauritian citrus fruit pulps. Food Research International, 44(7), 2088-2099.

Saracoglu, O. ve Altuntas, E. 2021. Assessment of Some Biotechnical Characteristics of Japanese Crabapple Depending on Fruit Size and Maturity Stage. Alınteri Journal of Agriculture Sciences, 36 (1), 21-26.

Singleton, V.L. ve Rossi, J.A. 1965. Colorimetry of total phenolics with phosphomolybdicphosphotungstic acid reagents. American journal of Enology and Viticulture, 16(3), 144-158.

Topuz, A., Topakci, M., Canakci, M., Akinci, I. ve Ozdemir, F. 2005. Physical and nutritional properties of four orange varieties. Journal of Food Engineering, 66:519-523.

Uslu, Ü.H. 2015. Kamkat Meyvesinin Ultrases (Ultrason) Destekli Kurutulması Ve Kalite Özelliklerinin Belirlenmesi. Süleyman Demirel Üniversitesi, Fen Bilimleri Enstitüsü. Gıda Mühendisliği Ana Bilim Dalı, Yüksek Lisans Tezi, Isparta.

Veeravenkatesh, M. ve Vishnuvardhan, S. 2014. Studies on some physical properties of sweet orange relevant to bulk handling. International Journal of Agricultural Engineering, 7(2): 347-351.

Vinci, G., Botrè, F., Mele, G. ve Ruggieri, G. 1995. Ascorbic acid in exotic fruits: a liquid chromatographic investigation. Food Chemistry, 53(2), 211-214.

Wang, Y.C., Chuang, Y.C. ve Ku, Y.H. 2007. Quantitation of bioactive compounds in citrus fruits cultivated in Taiwan. Food chemistry, 102(4), 1163-1171.

Yıldız Turgut D., Gölükcü, M. ve Tokgöz, H. 2015. Kamkat (Fortunella margarita Swing.) meyvesi ve reçelinin bazı fiziksel ve kimyasal özellikleri. Derim, 32 (1): 71-80.

Yılmaz, G., Altuntas, E., 2020. Some bio-technical properties of flax seeds, fennel seeds and harmal seed capsules. Turkish Journal of Agricultural Engineering Research (TURKAGER), 1(2): 222-232.

Zhishen, J., Mengcheng, T. ve Jianming, W. 1999. The determination of flavonoid contents in mulberry and their scavenging effects on superoxide radicals. Food chemistry, 64(4), 555-559. 